\title{
A model for transport of hydrogen sulfide in oil- and water-saturated porous media
}

\author{
Inge Skjælaaen - Anozie Ebigbo • \\ Magne Espedal · Rainer Helmig
}

Received: 21 October 2009 / Accepted: 2 September 2010 / Published online: 4 December 2010

(C) The Author(s) 2010. This article is published with open access at Springerlink.com

\begin{abstract}
In several oilfields, reservoir souring by generation of hydrogen sulfide $\left(\mathrm{H}_{2} \mathrm{~S}\right)$ occurs in secondary recovery during which seawater is injected into originally sweet reservoirs. At the production site, high concentrations of $\mathrm{H}_{2} \mathrm{~S}$ can cause severe damage to both equipment and human personnel. Proper modeling of $\mathrm{H}_{2} \mathrm{~S}$ concentration in produced fluids can be useful for decision-making during field development design. We present a model for the transport of $\mathrm{H}_{2} \mathrm{~S}$ in an oil- and water-saturated, water-wet porous medium. The different retardation mechanisms for the $\mathrm{H}_{2} \mathrm{~S}$ are described. For the adsorption of $\mathrm{H}_{2} \mathrm{~S}$ to rock, we include two distinct phases of adsorption. In addition, we introduce a functional relationship between adsorption capacity and permeability. As $\mathrm{H}_{2} \mathrm{~S}$ mixes with oil, fractions become immobile as part of the residual oil.
\end{abstract}

\section{Introduction}

It is well established that the main cause of reservoir souring is the growth of sulfate-reducing bacteria (SRB) which generate $\mathrm{H}_{2} \mathrm{~S}$. In [15], they present a one-dimensional, single-phase flow and reaction model for the transport of $\mathrm{H}_{2} \mathrm{~S}$

Communicated by Gabriel wittum.

This article is dedicated to the memory of our dear colleague, friend and mentor, Magne Espedal, who passed away during the preparation of this manuscript.

I. Skjælaaen $(\varangle) \cdot$ M. Espedal

Centre for Intregrated Petroleum Research,

Unifob, Norway

e-mail: inge@ skjaelaaen.com

A. Ebigbo $\cdot$ R. Helmig

Department of Hydromechanics and Modeling of Hydrosystems,

University of Stuttgart, Stuttgart, Germany in a water-saturated reservoir. They simulated two basic and distinct concepts for $\mathrm{H}_{2} \mathrm{~S}$ production due to growth of SRB: (1) growth takes place in the mixing zone of injected water and formation water as introduced in [12], and (2) in a novel approach, growth takes place in biofilms close to the injection well. $\mathrm{H}_{2} \mathrm{~S}$ production profiles from field data correlated with (2) and did not match with (1). A second novelty in their model was the modeling of the adsorption of $\mathrm{H}_{2} \mathrm{~S}$ to reservoir rock which was also crucial for the model to match the field data. In [6], a model for both generation and transport of $\mathrm{H}_{2} \mathrm{~S}$ in an oil-water system is presented. In the modeling of transport, they apply a partition coefficient that depends mainly on temperature and only weakly on pressure to determine the ratio of $\mathrm{H}_{2} \mathrm{~S}$ concentration in the two phases (oil and water). In our model, we consider a water-wet porous medium which is initially oil-filled to residual water saturation and into which water containing $\mathrm{H}_{2} \mathrm{~S}$ is injected. We do not include reaction processes, i.e., we do not model the generation of $\mathrm{H}_{2} \mathrm{~S}$. We assume that $\mathrm{H}_{2} \mathrm{~S}$ is generated by bacterial growth close to the injection well. Under the given conditions, oil and $\mathrm{H}_{2} \mathrm{~S}$ are assumed to be fully miscible, whereas a limited amount of $\mathrm{H}_{2} \mathrm{~S}$ may dissolve in water.

The objective of this paper is to present a qualitative model for the transport of $\mathrm{H}_{2} \mathrm{~S}$ in oil reservoirs, describing the different retardation mechanisms separately and in relation with the mathematical model. Comparing numerical results with field data is beyond the scope of this article as we perform only qualitative sensitivity tests for explanatory purposes. For a discussion on industrial applications of reservoir souring models, see [5].

In Sect. 2, we present the physical concept of the model. In Sect. 3, we present the mathematical model, and in Sects. 4 and 5, we describe the different retardation mechanisms. In Sect. 6, we briefly explain the numerical solution approach. 
In Sect. 7, we present sensitivity test examples, and concluding remarks are given in Sect. 8.

\section{Physical model}

Following the conclusions in [15], we assume that the sulfate-reducing bacteria (SRB) are able to live and reproduce, and hence generate $\mathrm{H}_{2} \mathrm{~S}$, only close to the injection well. The computational domain is defined such that the direction of production is from West to East, i.e., there is inflow at West and outflow at East. At the West boundary, there is inflow of $\mathrm{H}_{2} \mathrm{~S}$ and inside the domain there is no source/production of either $\mathrm{H}_{2} \mathrm{~S}$ or SRB. We assume no temporal or spatial variation for the temperature within the computational domain. The porous medium is assumed to be water-wet and initially oil-saturated up to residual water saturation. At the West boundary of the computational domain, the oil saturation is assumed to be zero such that the inflow is water containing $\mathrm{H}_{2} \mathrm{~S}$. We assume that $\mathrm{H}_{2} \mathrm{~S}$ and oil are miscible at reservoir conditions, hence $\mathrm{H}_{2} \mathrm{~S}$ does not form a separate phase.

\section{Mathematical model}

Here we present the mathematical setup for our specific model. For general multiphase multicomponent models, see e.g. [14].

The phases are oil $(o)$ and water $(w)$, and the components are oil, water and hydrogen sulfide, $\mathrm{H}_{2} \mathrm{~S}$, for simplicity denoted by $(g)$. We define $\alpha=(o, w)$ and $i=(o, w, g)$. For the phases $\alpha$, we define the relative permeability $k_{r \alpha}$, the viscosity $\mu_{\alpha}$, the pressure $p_{\alpha}$, the density $\rho_{\alpha}$ and the saturation $S_{\alpha}$. The absolute permeability tensor is denoted by $\mathbf{K}$. We assume that the variance in depth of the reservoir is small enough to set the gravitational acceleration $\mathbf{g}$ as a constant. The Darcy velocity $\mathbf{u}_{\alpha}$ for the phase $\alpha$ is then

$\mathbf{u}_{\alpha}=\frac{k_{r \alpha}}{\mu_{\alpha}} \mathbf{K}\left(\nabla p_{\alpha}-\rho_{\alpha} \mathbf{g}\right)$.

We define the diffusion coefficient $d_{\alpha}^{i}$ for component $i$ in phase $\alpha$ and the tortuosity $\tau_{\alpha}$ which is a measure for the irregularity of the flow paths. Using the approach introduced in [13], it is defined by

$\tau_{\alpha}=\frac{\left(\phi S_{\alpha}\right)^{7 / 3}}{\phi^{2}}$.

The diffusion tensor $\mathbf{D}_{\alpha}^{i}$ for the component $i$ in phase $\alpha$ is then given by

$\mathbf{D}_{\alpha}^{i}=\tau_{\alpha} \phi S_{\alpha} d_{\alpha}^{i} \mathbf{I}$

where $\mathbf{I}$ is the $m \times m$ identity matrix. $m$ is the number of spatial dimensions.
We define

$N_{i}=\sum_{\alpha=o, w} \rho_{\alpha} X_{\alpha}^{i} S_{\alpha}$

and

$F_{i}=\sum_{\alpha=o, w} \rho_{\alpha} \mathbf{u}_{\alpha} X_{\alpha}^{i}$,

where $X_{\alpha}^{i}$ is the mass fraction of component $i$ in phase $\alpha$. We define the amount $A_{i}$ of adsorbed mass of component $i$ to rock. This is discussed in Sect. 5. Finally, porosity $\phi$ is assumed to be constant in time, so that we have for $i=$ $(w, o, g)$ the following mass balance equation:

$\phi \frac{\partial\left(N_{i}+A_{i}\right)}{\partial t}+\nabla \cdot\left(F_{i}(p, T)\right)-\sum_{\alpha} \nabla \cdot\left(\mathbf{D}_{\alpha}^{i} \rho_{\alpha} \nabla X_{\alpha}^{i}\right)=0$.

Equation (6) represents three equations. In the case that both phases are present (other cases are discussed in Sect. 6.1), we solve Eq. (6) for the independent variables $S_{w}, p_{o}$ and $X_{o}^{g}$. To close the system, we need to determine the secondary variables as functions of the primary variables. First, we have that the saturations must satisfy

$S_{w}+S_{o}=1$.

We have the capillary pressure relation

$p_{c}=p_{o}-p_{w}$,

where the capillary pressure is set to be a function of the water saturation, $p_{c}=p_{c}\left(S_{w}\right)$. Relative permeability is also a function of saturation, $k_{r \alpha}=k_{r \alpha}\left(S_{\alpha}\right)$. The densities and viscosities may be functions of pressure and temperature, $\rho_{\alpha}=\rho_{\alpha}\left(p_{\alpha}, T\right)$ and $\mu_{\alpha}=\mu_{\alpha}\left(p_{\alpha}, T\right)$.

Further, we need functional relations between the mass fractions, relations through which important dynamics are modeled in our work. This is explained in the Sect. 4.

\section{Equilibrium equations}

The mass fractions of the components oil and water in the water and oil phases, respectively, are set to be functions of thermodynamical variables $\mathbf{T}=\left(p_{o}, p_{w}, T\right)$ :

$X_{w}^{o}=f_{1}(\mathbf{T})$,

and

$X_{o}^{w}=f_{2}(\mathbf{T})$.

The absorption of $\mathrm{H}_{2} \mathrm{~S}$ in oil and water is modeled through the determination of the mass fractions of $\mathrm{H}_{2} \mathrm{~S}$ in the two phases, and is explained in Sect. 4.1. 


\subsection{Partitioning of $\mathrm{H}_{2} \mathrm{~S}$}

The total amount of $\mathrm{H}_{2} \mathrm{~S}$ present is assumed to be instantaneously distributed in oil, water, and the surface of the rock, i.e., kinetics are not modeled. This is justified by the large ratio between the mass transfer velocities and the flow velocities. We explain the distribution of $\mathrm{H}_{2} \mathrm{~S}$ in the case where both phases are present, i.e., when $X_{o}^{g}$ is a primary variable. The solubility of $\mathrm{H}_{2} \mathrm{~S}$ in water is calculated using Henry's law:

$X_{w}^{g}=\frac{X_{o}^{g} p_{o}}{K_{H}(T)}$

where $K_{H}(T)$ is the Henry constant given by $[3,10]$ :

$$
\begin{aligned}
\log K_{H}(T)= & 84.44+0.0101845 T-\frac{3.792 \times 10^{3}}{T} \\
& -29.5008 \log (T) \quad[\mathrm{MPa}],
\end{aligned}
$$

where $T$ is in $\mathrm{K}$. The sum of mass fractions in one phase must satisfy

$\sum_{i} X_{\alpha}^{i}=1$

hence with the definitions above, all mass fractions are defined, and the system of equations is closed in a REV in which both phases are present. On the other hand, when only one of the phases is present, a change in the set of primary variables is necessary. This is explained in Sect. 6.1.

\section{Adsorption}

A fraction of the $\mathrm{H}_{2} \mathrm{~S}$ gets adsorbed by the rock. Water being the wetting phase in our model, we assume that the rate of adsorption of $\mathrm{H}_{2} \mathrm{~S}$ at the rock surface is a function of the concentration of $\mathrm{H}_{2} \mathrm{~S}$ in water and not directly dependent on $X_{o}^{g}$. The amount $A_{g}$ of adsorbed $\mathrm{H}_{2} \mathrm{~S}$ is then a function of $X_{w}^{g}$ and of thermodynamical variables:

$A_{g}=A_{g}\left(X_{w}^{g}, \mathbf{T}\right)$.

Note that no other adsorption processes are considered here, i.e., $A_{w}=A_{o}=0$. An adsorption capacity $C^{r}$ for the rock should define an upper limit for $A$, and $A$ should increase with increasing $X_{w}^{g}$. A simplistic approach to the adsorption function is:

$A_{g}=C^{r} \frac{X_{w}^{g}}{k+X_{w}^{g}}$,

where $k=k(\mathbf{T})$ is a function of thermodynamical variables. It is the value of $X_{w}^{g}$ at which half the adsorption capacity is reached. Note that in this approach, $A_{g}$ is a Langmuir isotherm [11], i.e., no kinetics are involved in the modeling of the adsorption. In [15], it is emphasized that no

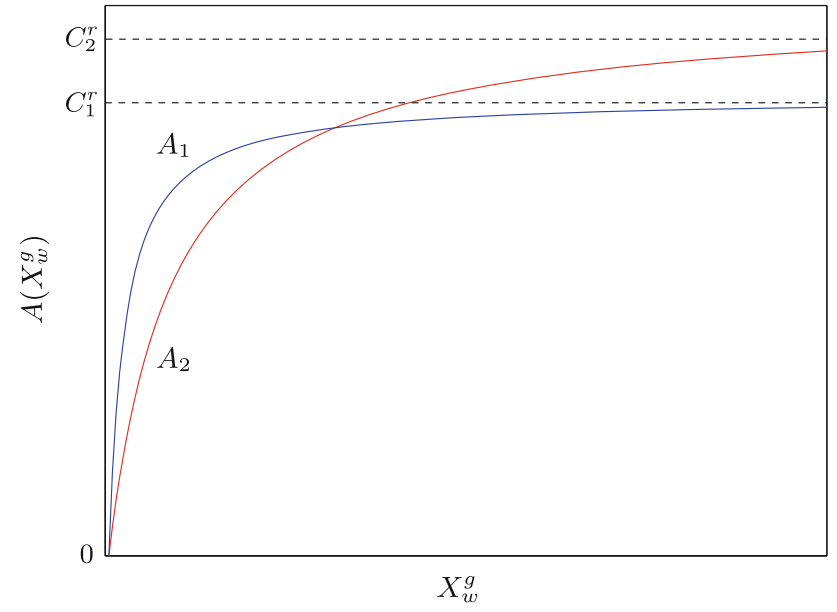

Fig. 1 Adsorption functions $A_{1}$ and $A_{2}$ for the two adsorption phases

isotherm can satisfy all the properties one would expect from the adsorption of $\mathrm{H}_{2} \mathrm{~S}$ at the rock, since the isotherm only depends on the concentration of $\mathrm{H}_{2} \mathrm{~S}$ in the fluid and does not take into account the amount of currently adsorbed $\mathrm{H}_{2} \mathrm{~S}$. They point out that the adsorption process consists of two phases, the first of which has a higher affinity and lower capacity than the second. To approach the distinction of the two phases of adsorption, we define two adsorption functions $A_{1}\left(X_{w}^{g}, k_{1}, C_{1}^{r}\right)$ and $A_{2}\left(X_{w}^{g}, k_{2}, C_{2}^{r}\right)$ for the first and the second phase, with $C_{1}^{r}<C_{2}^{r}$ and $k_{1}<k_{2}$, see Fig. 1. For a given set of parameters and $\mathrm{H}_{2} \mathrm{~S}$ concentration in water, $A$ is then chosen such that $A=\max \left(A_{1}, A_{2}\right)$.

5.1 Adsorption capacity related to permeability, porosity and surface area

The adsorption capacity is related to the surface area of the reservoir rock. It is not straightforward how to include this relation in a Darcy-scale model, and here we present our approach. In Kozeny's equation, porosity $\phi$, surface area $M$ and permeability $K$ (here considered a scalar) are related by:

$K=c \cdot \frac{\phi^{3}}{M^{2}}$

where $c$, called Kozeny's constant, varies with the geometrical shape of the pore channels [2]. We define reference values $\phi_{0}, M_{0}$, and $K_{0}$ at a point $\left(x_{0}, y_{0}\right)$, and have that

$\frac{K}{K_{0}}=\left(\frac{\phi}{\phi_{0}}\right)^{3}\left(\frac{M_{0}}{M}\right)^{2}$.

To reduce the degrees of freedom, we assume that changes in $\phi$ are much smaller than changes in $K$ or $M$ and neglect its effect in the equation. We therefore have

$K=K_{0}\left(\frac{M_{0}}{M}\right)^{2}$. 
Finally we relate the adsorption capacity with the surface area by

$$
\begin{aligned}
& C_{1}^{r}=C_{1,0}^{r} \frac{M}{M_{0}}, \\
& C_{2}^{r}=C_{2,0}^{r} \frac{M}{M_{0}} .
\end{aligned}
$$

\section{Numerical model}

We use the numerical simulator MUFTE-UG, developed at University of Stuttgart and University of Heidelberg see $[1,8]$. UG is a general platform for solving partial differential equations, and the MUFTE part is where the discretized equations are specified. The latter is briefly explained in the following. A fully implicit Euler scheme is applied for the storage term. For spatial discretization, the BOX method [7] is applied. The BOX method is locally mass conservative and can be used for unstructured grids. For stable and non-oscillating solutions, a fully upwind technique is applied for the advection term, whereas non-physical spatial oscillations are avoided by the mass lumping technique [9]. The non-linear system of three coupled partial differential equations is linearized by the Newton-Raphson method, and line search is carried out to evaluate the need for time step reduction.

\subsection{Adaptive choice of primary variables}

As Eq. (6) represents three independent equations, we have to determine three independent primary variables in order to describe the thermodynamical state of the system. The choice of the primary variables must be consistent with the phase state. It must be possible to calculate all secondary variables from the primary variables. For instance, if only water is present then the amount of $\mathrm{H}_{2} \mathrm{~S}$ in water cannot be calculated through the amount of $\mathrm{H}_{2} \mathrm{~S}$ in oil, hence $X_{w}^{g}$ must be a primary variable, and accordingly for $X_{w}^{o}$. The primary variables are switched when the solution for the current set of primary variables becomes non-physical. For example, given a situation in which both phases are initially present, one of the two phases may disappear if the solution for its saturation becomes negative. In this case, the initial primary variable, i.e., the saturation, is replaced by the mass fraction of that component in the phase which is still present. In a singlephase system, on the other hand, the appearance of a second phase is warranted if the mass fraction of a component in the phase exceeds its solubility limit. In this case, the mass fraction is substituted by a saturation as the primary variable. In Table 1, the different phase states and the corresponding sets of primary variables are listed.
Table 1 Phase states and corresponding primary variables

\begin{tabular}{lll}
\hline Phase state & Phases present & Primary variables \\
\hline Oil phase & Oil $(o)$ & $X_{o}^{w}, p_{o}, X_{o}^{g}$ \\
Water phase & Water $(w)$ & $X_{w}^{o}, p_{w}, X_{w}^{g}$ \\
Both phases & $w, o$ & $S_{w}, p_{o}, X_{o}^{g}$ \\
\hline
\end{tabular}

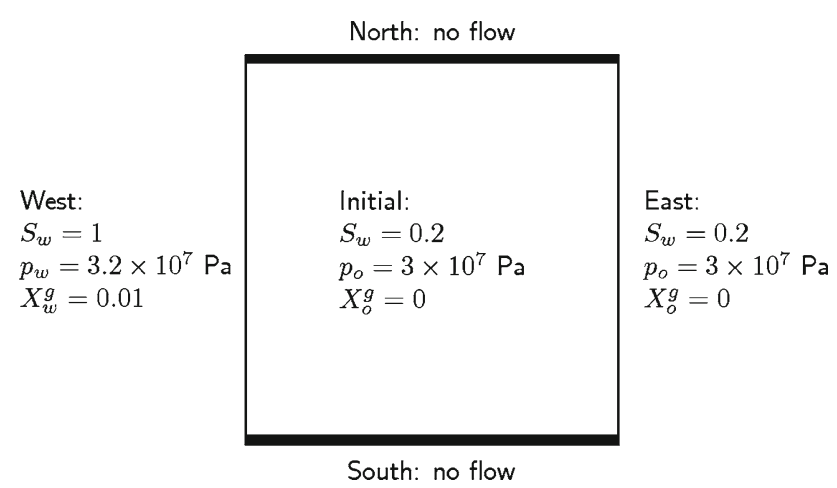

Fig. 2 Boundary and initial conditions for the standard case simulation

For a schematic overview of the algorithms and more on the switch in primary variables, see e.g. [4].

\section{Simulations}

Here, we present a qualitative sensitivity test study. The reservoir is small and two-dimensional, $10 \times 10 \mathrm{~m}^{2}$, for the sake of computational efficiency. First, we show a standard case simulation for which the boundary conditions, the initial conditions and the parameters are given in Table 2 and Fig. 2. Water is injected into an initially oil-filled (i.e., residually saturated with water) and $\mathrm{H}_{2} \mathrm{~S}$-free reservoir. This is achieved by setting constant values at the western and eastern boundaries, while the northern and southern boundaries are assumed to be impermeable. The conditions at the East are identical to the initial conditions. At the West, inflow of water is ensured by assigning a higher pressure at the boundary than within the domain and, assuming that the boundary is sufficiently near to the injection well, a water saturation of unity. The water entering the domain is assumed to contain a given amount of $\mathrm{H}_{2} \mathrm{~S}$ produced by bacteria near the injection well - hence $X_{w}^{g}=0.01$ is set at the western boundary.

The results are presented in Fig. 3, where the flux of oil, water and $\mathrm{H}_{2} \mathrm{~S}$ at the East boundary, i.e., close to production well, are plotted as a function of time. We see that the water breakthrough takes place after three days, while $\mathrm{H}_{2} \mathrm{~S}$ is not produced before the the eleventh day, approximately. This retardation of the transport of $\mathrm{H}_{2} \mathrm{~S}$ within the domain is caused by the mixing of the $\mathrm{H}_{2} \mathrm{~S}$ with the residual oil and adsorption at the surface of the rock. The parameters which control the character of the simulation results are the 
Table 2 Standard case setup

\section{Parameters}

Temperature

Porosity

Absolute permeability

Residual water saturation, $S_{w r}$

Residual oil saturation, $S_{\text {or }}$

Density water

Density oil

Viscosity water

Viscosity oil

Solubility oil in water, $X_{w}^{o}$

Solubility water in oil, $X_{o}^{w}$

Adsorption capacities; first phase $C_{1}^{r}$, second phase $C_{2}^{r}$

Adsorption function coefficients, $k_{1}, k_{2}$

Diffusion coefficient $d_{o}^{\mathrm{H}_{2} \mathrm{~S}}$

Diffusion coefficient $d_{w}^{\mathrm{H}_{2} \mathrm{~S}}$

$p_{c}-S_{w}$ relationship

n

Relative permeability, water

$n$

Relative permeability, oil

$n$

Boundary conditions

$\begin{array}{llll}\text { Boundary } & \text { Type } & \text { State } & \text { Variable } \\ \text { West } & \text { Dirichlet } & \text { Water phase } & X_{w}^{o} \\ & & & p_{w} \\ & & & X_{w}^{g} \\ \text { East } & \text { Dirichlet } & \text { Both phases } & S_{w} \\ & & & p_{o} \\ & & & X_{o}^{g} \\ \text { North } & \text { Neumann } & \text { Both phases } & q_{w} \\ & & & q_{o} \\ & & & q_{\mathrm{H}_{2} \mathrm{~S}} \\ \text { South } & & & q_{w} \\ & & \text { Both phases } & \\ & & & \end{array}$

Initial conditions

Variable

$S_{w}$

$p_{o}$

$X_{o}^{g}$

Phase state

Value

0.2

0
$363.15 \mathrm{~K}$

0.15

$2.0 \times 10^{-14} \mathrm{~m}^{2}$

0.2

0.2

$1100 \mathrm{~kg} / \mathrm{m}^{3}$

$750 \mathrm{~kg} / \mathrm{m}^{3}$

$0.5534 \times 10^{-3} \mathrm{~Pa} \cdot \mathrm{s}$

$1.0322 \times 10^{-3} \mathrm{~Pa} \cdot \mathrm{s}$

0

0

$C_{1}^{r}=2, C_{2}^{r}=2.4 \mathrm{~kg} / \mathrm{m}^{3}$

$k_{1}=4.5 \times 10^{-4}, k_{2}=4 k_{1}$

$1.0 \times 10^{-9} \mathrm{~m}^{2} / \mathrm{s}$

$1.0 \times 10^{-9} \mathrm{~m}^{2} / \mathrm{s}$

van Genuchten: $\left.p_{c}=\frac{1}{\alpha}\left(S_{e}^{-1 / m}-1\right)^{1 / n}\right)$

$m=1-1 / n$

$S_{e}=\frac{S_{w}-S_{w r}}{1-S_{w r}-S_{o r}}$, for $1-S_{o r}>S_{w}>S_{w r}$

$2.8 \times 10^{-4}$

1.67

van Genuchten: $k_{r w}=\sqrt{S_{e}}\left[1-\left(1-S_{e}^{1 / m}\right)^{m}\right]^{2}$

1.67

van Genuchten: $k_{r o}=\sqrt{1-S_{e}}\left[1-S_{e}^{1 / m}\right]^{2 m}$

1.67

$\begin{array}{lll}\text { Value } & \text { Unit } & \text { Comment } \\ 0.0 & - & \\ 3.2 \times 10^{7} & \mathrm{~Pa} & \\ 0.01 & - & \\ 0.2 & - & \\ 3.0 \times 10^{7} & \mathrm{~Pa} & \\ 0.0 & - & \\ 0.0 & \mathrm{~kg} / \mathrm{m}^{2} \mathrm{~s} & \text { no flow (water) } \\ 0.0 & \mathrm{~kg} / \mathrm{m}^{2} \mathrm{~s} & \text { no flow (oil) } \\ 0.0 & \mathrm{~kg} / \mathrm{m}^{2} \mathrm{~s} & \left.\text { no flow ( } \mathrm{H}_{2} \mathrm{~S}\right) \\ 0.0 & \mathrm{~kg} / \mathrm{m}^{2} \mathrm{~s} & \text { No flow (water) } \\ 0.0 & \mathrm{~kg} / \mathrm{m}^{2} \mathrm{~s} & \text { No flow (oil) } \\ 0.0 & \mathrm{~kg} / \mathrm{m}^{2} \mathrm{~s} & \left.\text { No flow (H } \mathrm{H}_{2} \mathrm{~S}\right)\end{array}$

Unit

$3.0 \times 10^{7}$

Both phases
-

$\mathrm{Pa}$

$-$ 


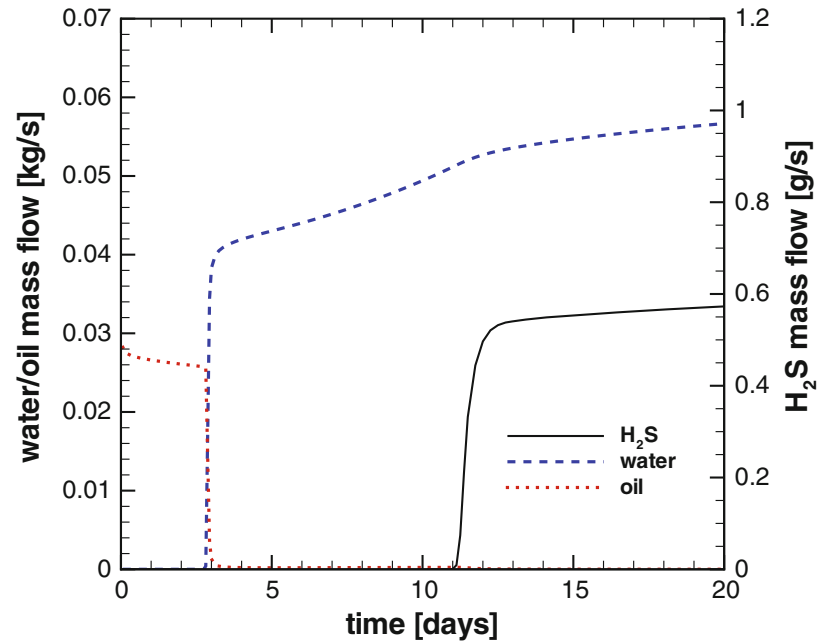

Fig. 3 Fluxes of oil, water and $\mathrm{H}_{2} \mathrm{~S}$ at production for the standard case simulation

residual oil saturation, the adsorption capacity of the rock and the amount of $\mathrm{H}_{2} \mathrm{~S}$ flowing into the domain. In the following, simulations conducted in order to study the variation of these parameters are presented. Finally, we present a test case with a heterogeneous permeability field which affects the adsorption capacities through the effective rock surface area. The results from all simulations are compared with the standard case.

\subsection{Variation of the residual oil saturation}

As oil mixes with $\mathrm{H}_{2} \mathrm{~S}$ from the injected water, a fraction of the $\mathrm{H}_{2} \mathrm{~S}$ will remain in the residual oil. The higher the residual oil saturation, the more $\mathrm{H}_{2} \mathrm{~S}$ is immobilized as it mixes with the residual oil. In the standard case, $S_{o r}=0.2$. In Fig. 4a, results for $S_{o r}=0.1$ show a later water breakthrough than in the standard case due to the larger amount of pore space available for the water phase. On the other hand, $\mathrm{H}_{2} \mathrm{~S}$ breaks through earlier since the capacity of immobilization due to mxing with residual oil is reduced. Accordingly, in Fig. 4b, where $S_{o r}=0.4$, the water breakthrough takes place earlier, and $\mathrm{H}_{2} \mathrm{~S}$ reaches the production site later.

\subsection{Variation of the adsorption capacity}

In Fig. 5a, the adsorption capacities are halved compared to the standard case such that $C_{1}^{r}=1 \mathrm{~kg} / \mathrm{m}^{3}$ and $C_{2}^{r}=1.2$ $\mathrm{kg} / \mathrm{m}^{3}$. We see that water breakthrough has not changed from the standard case (which is obvious since the flow of water is not depndent on the adsorption of $\mathrm{H}_{2} \mathrm{~S}$ ), but the $\mathrm{H}_{2} \mathrm{~S}$ reaches production faster than in the standard case since a smaller amount of $\mathrm{H}_{2} \mathrm{~S}$ can be immobilized due to adsorption. When doubling the adsorption capacities such that $C_{1}^{r}=4 \mathrm{~kg} / \mathrm{m}^{3}$ and $C_{2}^{r}=4.8 \mathrm{~kg} / \mathrm{m}^{3}$, we see from Fig. $5 \mathrm{~b}$ that $\mathrm{H}_{2} \mathrm{~S}$ reaches

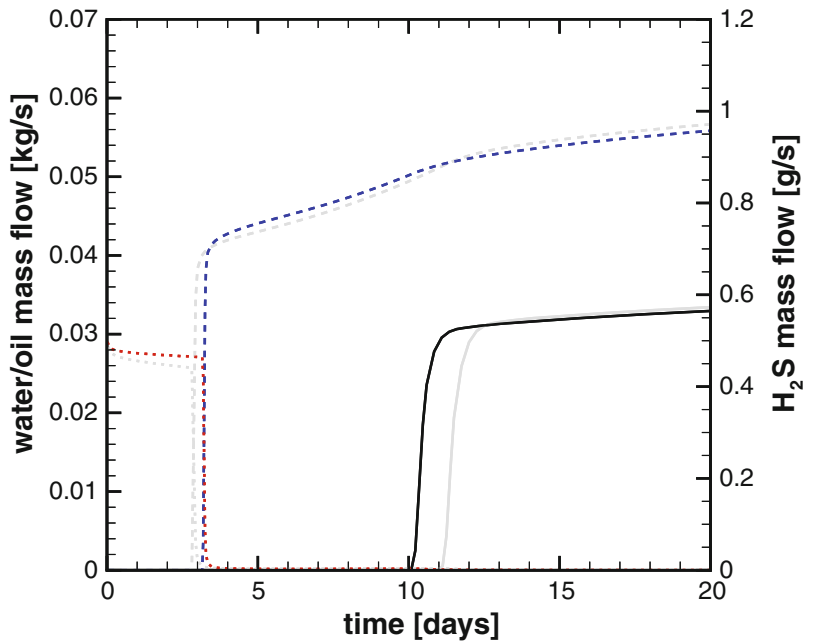

(a)

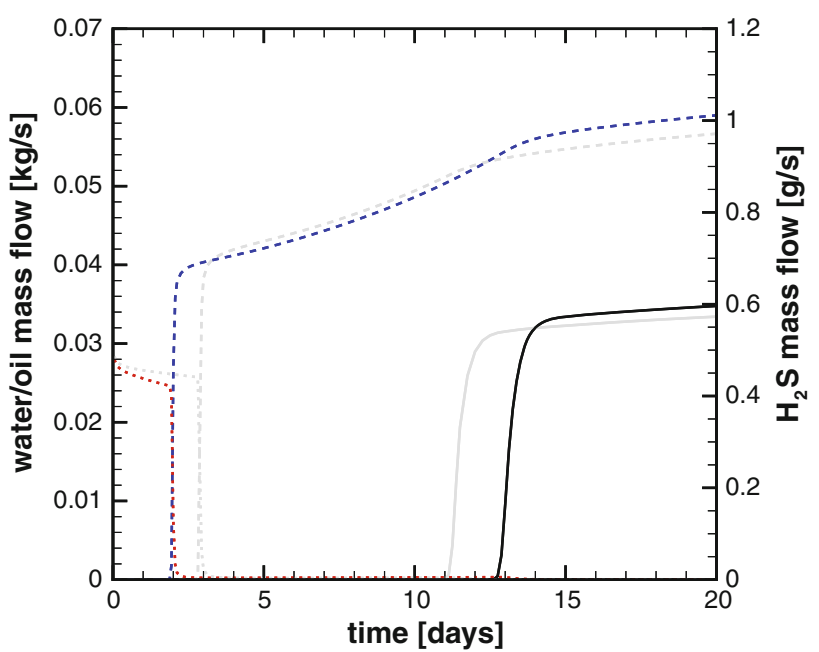

(b)

Fig. 4 Fluxes of oil, water and $\mathrm{H}_{2} \mathrm{~S}$ at production for different residual oil saturation values. The continous line represents the $\mathrm{H}_{2} \mathrm{~S}$ flux, the dashed line is the water flux, and the oil flux is depicted with the dotted line. The results of the standard case simulation are shown in gray. a Lower residual oil saturation, $S_{o r}=0.1$. b Higher residual oil saturation $S_{o r}=0.4$

production much later than in the standard case, while water breakthrough is not changed. In both cases, the adsorption function parameters $k_{1}, k_{2}$ (see Sect. 5 and Table 2) are not changed from the standard case.

Note that the changes in residual oil saturation and adsorption capacity have a very limited effect on the flux of $\mathrm{H}_{2} \mathrm{~S}$ after breakthrough (i.e., at steady state).

\subsection{Variation of rate of $\mathrm{H}_{2} \mathrm{~S}$ generation}

In Fig. 6, results from simulations with lower and higher amounts of $\mathrm{H}_{2} \mathrm{~S}$ in the injected water, are shown. In the case resulting in Fig. 6a, the mass fraction of $\mathrm{H}_{2} \mathrm{~S}$ in water at 


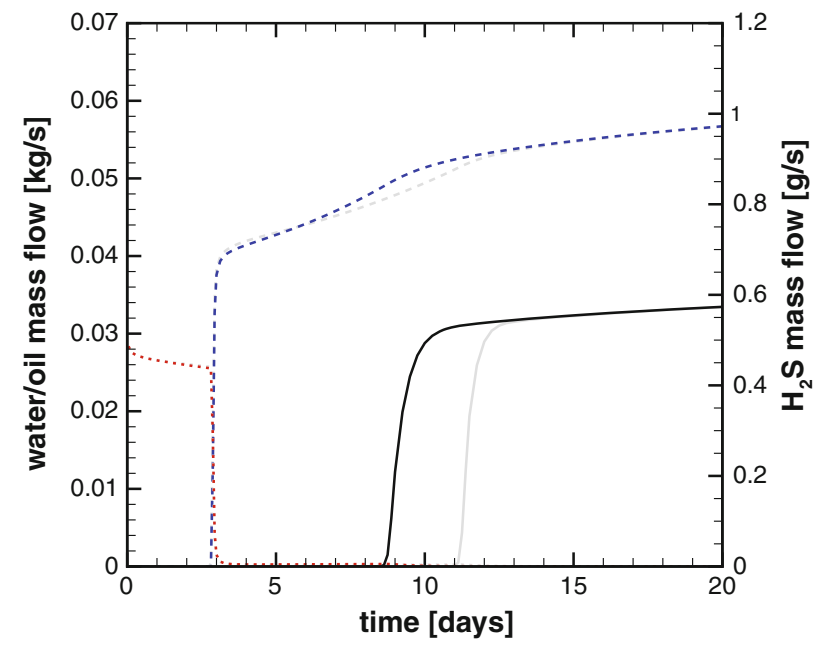

(a)

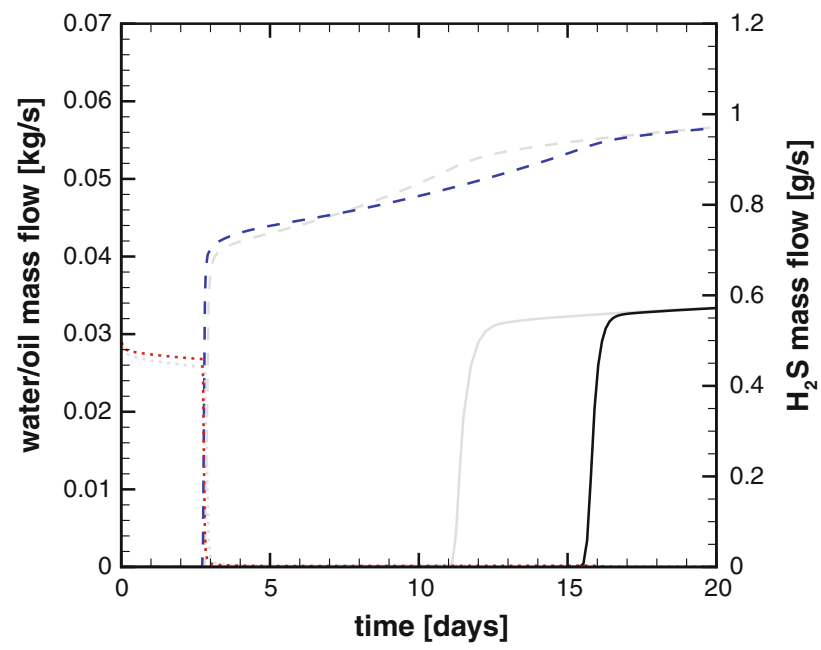

(b)

Fig. 5 Fluxes of oil, water and $\mathrm{H}_{2} \mathrm{~S}$ at production for different sets of adsorption capacities. The continous line represents the $\mathrm{H}_{2} \mathrm{~S}$ flux, the dashed line is the water flux, and the oil flux is depicted with the dotted line. The results of the standard case simulation are shown in gray. a Lower adsorption capacities, $C_{1}^{\tau}=1, C_{2}^{\tau}=1.2$. $\mathbf{b}$ Higher adsorption capacities, $C_{1}^{\tau}=4, C_{2}^{\tau}=4.8$

injection is halved compared to the standard case such that $X_{w}^{g}=0.05$. We see that $\mathrm{H}_{2} \mathrm{~S}$ reaches production later than in the standard case, and that the flux is also lower, both as expected. In Fig. 6b, results from doubling the mass fraction of $\mathrm{H}_{2} \mathrm{~S}$ in water at injection are shown. As expected, $\mathrm{H}_{2} \mathrm{~S}$ reaches production earlier and with a higher flux than in the standard case.

\subsection{Heterogeneous permeability field}

Here, we present a simulation in which the permeability field is heterogeneous; see Fig. 7a. All other parameters and initial conditions are as in the standard case. In Sect. 5.1, relations

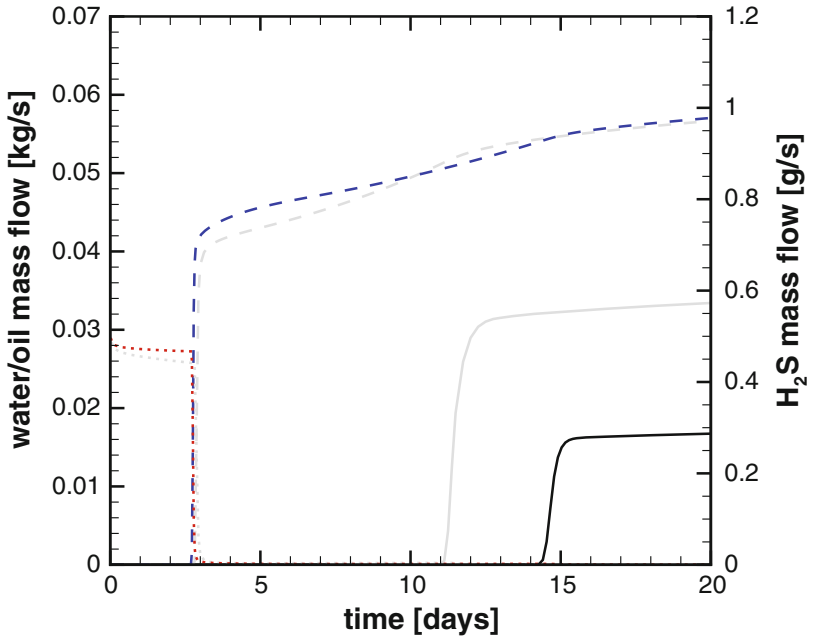

(a)

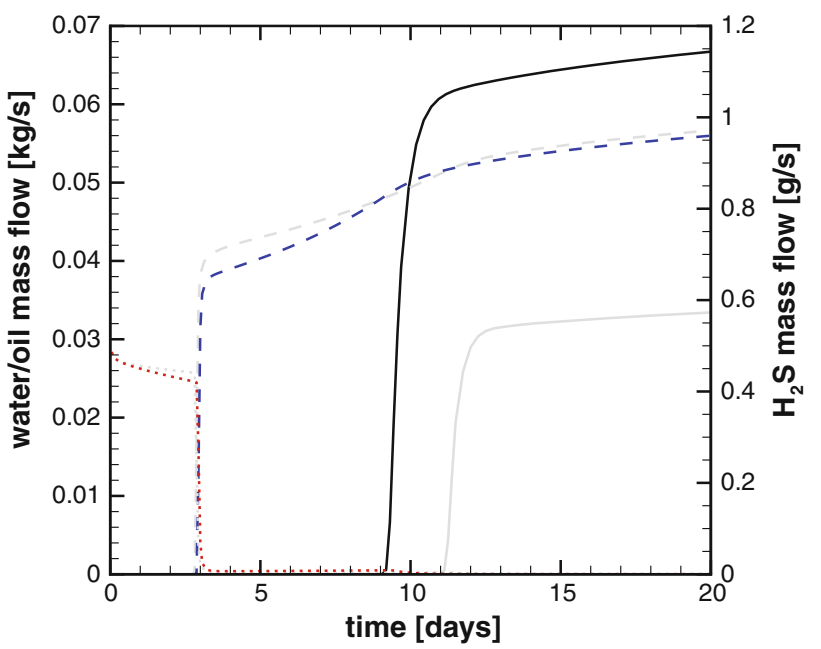

(b)

Fig. 6 Fluxes of oil, water and $\mathrm{H}_{2} \mathrm{~S}$ at production for different amounts of injected $\mathrm{H}_{2} \mathrm{~S}$. The continous line represents the $\mathrm{H}_{2} \mathrm{~S}$ flux, the dashed line is the water flux, and the oil flux is depicted with the dotted line. The results of the standard case simulation are shown in gray. a Lower $\mathrm{H}_{2} \mathrm{~S}$ injection, $X_{w}^{g}=.05$. b Higher $\mathrm{H}_{2} \mathrm{~S}$ injection, $X_{w}^{g}=.2$

between porosity, rock surface area and adsorption capacity are explained. The values for $C_{1,0}^{r}$ and $C_{2,0}^{r}$ are identical those of $C_{1}^{r}$ and $C_{2}^{r}$, respectively, of the standard case simulation. In the given field, the total adsorption capacity of the domain is equal to that of the standard case simulation.

In Fig. 7b, c, the distribution of adsorbed $\mathrm{H}_{2} \mathrm{~S}$ by the rock after 6 and 20 days, respectively, is shown. As expected, the amount of adsorbed $\mathrm{H}_{2} \mathrm{~S}$ is low in high permeable zones, and high in low permeable zones. Between the extrema, the permeability field and the adsorption distribution field are not linearly related. In Fig. 8, we see that, due to preferential pathways, the water front as well as the $\mathrm{H}_{2} \mathrm{~S}$ front are not as sharp as in the standard case. In addition, since less $\mathrm{H}_{2} \mathrm{~S}$ gets adsorbed in high permeable zones (see Fig. 7b) through 


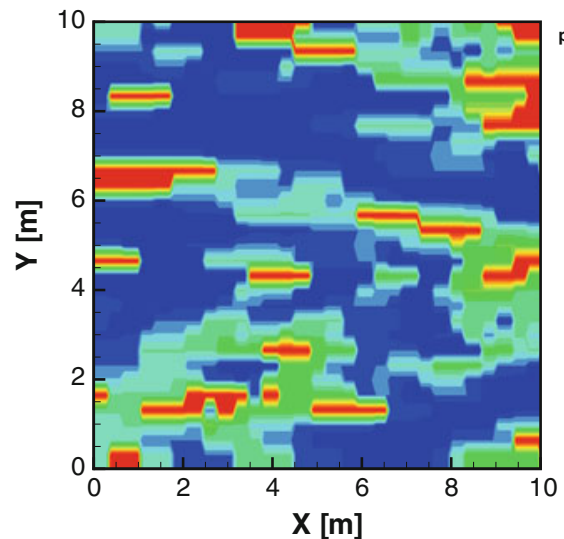

permeability $[\mathrm{mD}]$

(a)

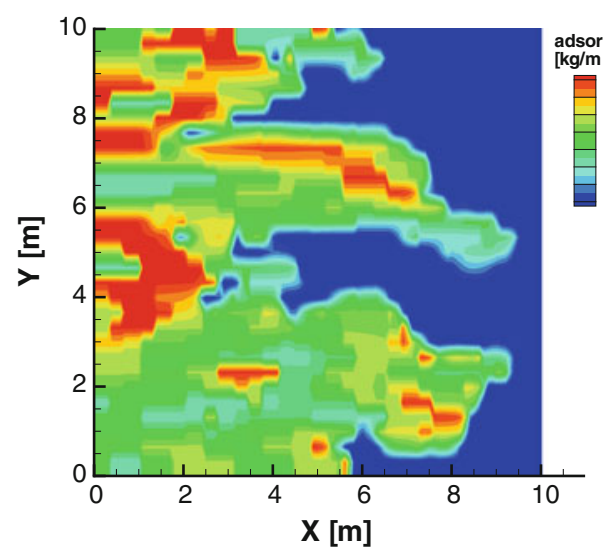

(b)

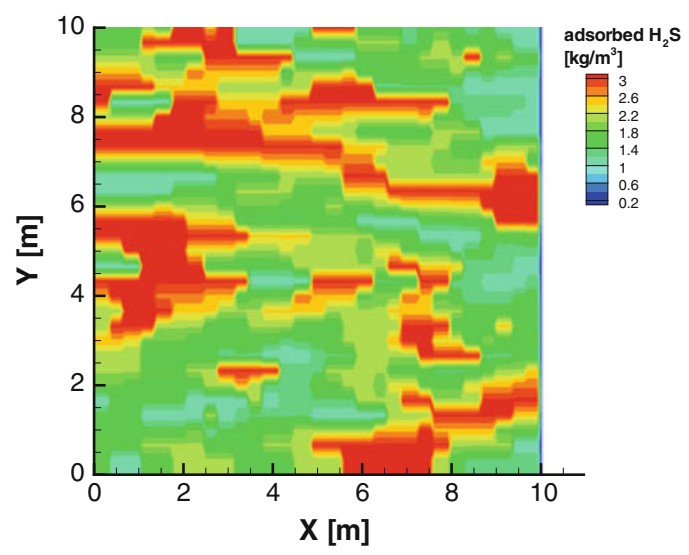

(c)

Fig. 7 Comparison of permeability field and distribution of adsorbed $\mathrm{H}_{2} \mathrm{~S}$ at $t=6$ days and $t=20$ days. a Heterogeneous permeability field. b Distribution of abosrbed $\mathrm{H}_{2} \mathrm{~S}$ at $t=6$ days. c Distribution of adsorbed $\mathrm{H}_{2} \mathrm{~S} t=20$ days

which most of the water flows, some $\mathrm{H}_{2} \mathrm{~S}$ reaches production earlier than in the standard case.

\section{Concluding remarks}

We have presented a model for the transport of hydrogen sulfide $\left(\mathrm{H}_{2} \mathrm{~S}\right)$ in oil reservoirs. Water containing dissolved

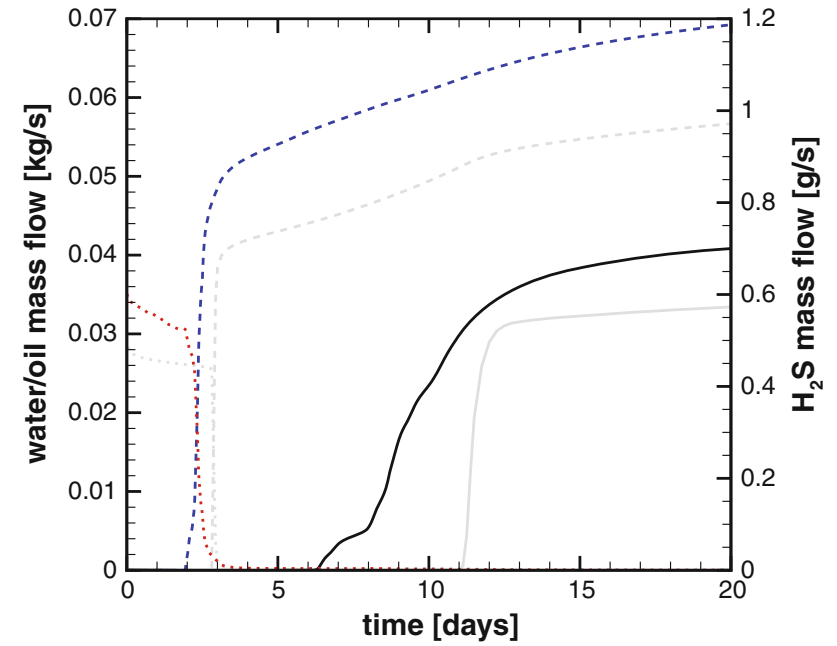

Fig. 8 Fluxes of oil, water and $\mathrm{H}_{2} \mathrm{~S}$ at production for heterogeneous permeability field shown in Fig. 7a, compared to the standard case. The continous line represents the $\mathrm{H}_{2} \mathrm{~S}$ flux, the dashed line is the water flux, and the oil flux is depicted with the dotted line. The results of the standard case simulation are shown in gray

$\mathrm{H}_{2} \mathrm{~S}$ is injected into an initially oil-filled, water-wet reservoir. The water breakthrough generally occurs before $\mathrm{H}_{2} \mathrm{~S}$ reaches production due to two retardation mechanisms: (1) mixing of $\mathrm{H}_{2} \mathrm{~S}$ with oil so that fractions remain in the residual oil and (2) adsorption of $\mathrm{H}_{2} \mathrm{~S}$ on the rock surface. An increase in residual oil saturation should result in later $\mathrm{H}_{2} \mathrm{~S}$ production, and a decrease should result in earlier $\mathrm{H}_{2} \mathrm{~S}$ production, as shown by simulations. An increase in the adsorption capacity of the rock is also shown to result in a later $\mathrm{H}_{2} \mathrm{~S}$ breakthrough. The breakthrough time also depends on the amount of injected $\mathrm{H}_{2} \mathrm{~S}$ as shown by simulation examples. Finally, a test example is given for the permeability-adsorption capacity relation.

Open Access This article is distributed under the terms of the Creative Commons Attribution Noncommercial License which permits any noncommercial use, distribution, and reproduction in any medium, provided the original author(s) and source are credited.

\section{References}

1. Bastian, P., Birken, K., Johannsen, K., Lang, S., Neuss, N., RentzReichert, H., Wieners, C.: UG-a flexible software toolbox for solving partial differential equations. Comput. Vis. Sci. 1(1), 27-40 (1997)

2. Bear, J.: Dynamics of Fluids in Porous Media. Dover Publications, New York (1988)

3. Chapoy, A., Mohammadi, A.H., Tohidi, B., Richon, D.: Estimation of water content for methane+ water and methane+ ethane+ n-butane+ water systems using a new sampling device. J. Chem. Eng. Data 50(4), 1157-1161 (2005)

4. Class, H., Helmig, R., Bastian, P.: Numerical simulation of nonisothermal multiphase multicomponent processes in porous media. 1. An efficient solution technique. Adv. Water Resour. 25(5), 533-550 (2002) 
5. De Siqueira, A., Araujo, C.H., Reksidler, R., Pereira, M.: Uncertainty analysis applied to biogenic reservoir souring simulation. In: EUROPEC/EAGE Conference and Exhibition (2009)

6. Bryant, S.L., Sepehrnoori, K., Farhadinia, M.A., Delshad, M.: Development of a reservoir simulator for souring predictions. In: SPE Reservoir Simulation Symposium (2009)

7. Helmig, R.: Multiphase Flow and Transport Processes in the Subsurface a Contribution to the Modeling of Hydrosystems Environmental Engineering (Berlin). Springer, New York (1997)

8. Helmig, R., Braun, C., Emmert, M.: MUFTE: A Numerical Model for Simulation of Multiphase Flow Processes in Porous and Fractured Porous Media. Programmdokumentation (HG208) (1994)

9. Huber, R., Helmig, R.: Multiphase flow in heterogeneous porous media: A classical finite element method versus an implicit pressure-explicit saturation-based mixed finite element-finite volume approach. Int. J. Numer. Methods Fluids 29(8), (1999)

10. Iliuta, I., Larachi, F.: Trickle bed mechanistic model for (non-) Newtonian power-law foaming liquids. Chem. Eng. Sci. 64(8), 1654-1664 (2009)
11. Langmuir, I.: The constitution and fundamental properties of solids and liquids. II. Liquids. J. Am. Chem. Soc. 39(9), 1848-1906 (1917)

12. Ligthelm, D.J., RB, Brint, J.F., Schulte, W.M.: Reservoir souring: an analytical model for $\mathrm{H} 2 \mathrm{~S}$ generation and transportation in an oil reservoir owing to bacterial activity. In Offshore Europe Conference, Aberdeen 3-6 September 1991 (1991)

13. Millington, R.J., Quirk, J.P.: Permeability of porous solids. Trans. Faraday Soc. 57, 1200-1207 (1961)

14. Qin, G., Wang, H., Ewing, R.E., Espedal, M.S.: Numerical simulation of compositional fluid flow in porous media. Numerical Treatment of Multiphase Flows in Porous Media, pp. 232-243 (2000)

15. Sunde, E., Thorstenson, T., Torsvik, T., Vaag, J.E., Espedal, M.S.: Field-related mathematical model to predict and reduce reservoir souring. In: Proceedings of SPE International Symposium on Oilfield Chemistry, New Orleans (1993) 